\title{
Determination of representative elementary volume (REV) for jointed rock masses exhibiting scale- dependent behavior: A numerical investigation
}

Mehmet Sari ( $\triangle$ mehmetsari@aksaray.edu.tr )

Aksaray University https://orcid.org/0000-0001-9441-9256

\section{Research Article}

Keywords: REV size, Scale effect, Open-pit mining, Numerical modeling, Jointed rock mass

Posted Date: August 26th, 2021

DOl: https://doi.org/10.21203/rs.3.rs-847473/v1

License: (c) (1) This work is licensed under a Creative Commons Attribution 4.0 International License.

Read Full License

Version of Record: A version of this preprint was published at International Journal of Geo-Engineering on December 1st, 2021. See the published version at https://doi.org/10.1186/s40703-021-00164-1. 


\section{Abstract}

Representative elementary volume (REV) is defined as the usual size of a rock mass structure beyond which its mechanical properties are homogenous and isotropic, and its behavior can be modeled using the equivalent continuum approach. Determination of REV is a complex problem in rock engineering due to its definition ambiguity and application area. This study is one of the first attempts to define a REV for jointed rock masses using the equivalent continuum approach. It is aimed to numerically search a ratio between the characteristic size of an engineering structure and pre-existing joint spacing, which are the two most important contributing elements in assessing REV. For this purpose, four hypothetical engineering cases were investigated using the RS2 (Phase2 v. 9.0) finite element (FE) analysis program. An underground circular opening with a constant diameter, an open-pit mine with varying bench heights, a single bench with a constant height, and an underground powerhouse cavern with a known dimension were executed for possible changes in the safety factor and total displacement measurements under several joint spacing values. Different cut-off REVs were calculated for FE models depending on the type of excavation and measurement method. An average REV size of 19.0, ranging between a minimum of 2 for tunnels and a maximum of 48 for slopes, was found in numerical analysis. The calculated sizes of REV were significantly larger than the range of values (5 to 10) commonly reported in the relevant geotechnical literature.

\section{Introduction}

The mechanical behavior (strength and stiffness) of rock masses surrounding engineering structures is always a concern in rock engineering studies. These structures are excavated in/on a complex material composed of intact rock blocks tightly delineated by ubiquitous joints (Sainsbury and Sainsbury 2017). A proper characterization of rock mass behavior must consider the combined effects of both in-situ rock blocks and joints. While discontinuities can play a dominant role in defining their mechanical behavior, they can also make it difficult to precisely predict jointed rock masses' strength and deformation characteristics (Hoek and Brown 1997). Whether the structures in/on rock masses are close to the surface or deep underground has certain effects on their mechanical behavior due to the induced stresses. Opening underground excavations in deep hard rock mines may lead to two types of failure: (1) structurally controlled gravity-driven failure and (2) stress-induced failure (Hoek et al. 1995). The former is predominant when both the radial and the tangential stresses are low; however, the latter is prevalent when tangential stresses are high. Structurally controlled failures are most frequently observed at shallow depths (50 m-200 m), while stress-driven failures are commonly found at great depths (>1000m). Consequently, it is always challenging for rock engineering to study the rock masses' mechanical behavior, displaying a wide array from a simple brittle failure of an intact core sample to a complex masscontrolled failure of the overall pit slope (Fig. 1).

[Figure 1] 
Heuze (1980) performed a literature review to investigate the effect of test volume on the strength and stiffness capacities of rock masses. He concluded that laboratory tests on small samples were not adequate to represent the strength and deformability of rock masses on the field scale. Size-dependent behavior is believed to be caused by a larger rock mass volume tending to have more defects. When the size of rock structures increases, so does the number of discontinuities, micro-cracks, etc., within a problem under investigation. Due to the greater possibility of weak planes presenting with a large volume, they are also likely to have a lower strength and deformation modulus at an increasing scale (Bobet et al. 2009).

Scaling effects also need to be considered in principle in underground structures. Two major stability problems can be encountered in underground structures related to scale-dependent behavior and impact underground structures' design. First is the gravity-induced, structurally controlled block movement in wedges or falls-of-ground at shallow depths, and second is stress-induced spalling or slabbing found in brittle, blocky, and massive rock masses at higher depths (Martin et al. 1999). There are also specific conditions where scale dependency can be ignored. For instance, in analyzing brittle failure in rocks, the uniaxial compressive strength (UCS) of intact rock is used to predict and assess spalling depth. It is assumed that brittle failure occurs in competent rock masses, and a small sample can be a good representative of the entire mass (Salmi, 2019).

\subsection{Causes of Scale-Dependent Behavior}

A jointed rock mass is defined by the presence of fracture defects between intact rock blocks. These can be large-scale geological structures, such as faults and dykes extending for tens to hundreds of meters or medium-scale fractures, e.g., joints, bedding planes, and foliations, ranging from a few centimeters to tens of meters. The presence of discontinuities generates stress concentration/relaxation areas, which can significantly impact the mechanical behavior of the rock mass because joint intersections are often areas of high stress and deformation counters, damage, and failure (Mas Ivars, 2010). They can also cause a significant size effect on the mechanical and hydraulic response of a rock mass (Song et al. 2017). Indeed, in the design of large excavations (both surface and underground) in jointed rocks, ignoring scale dependency can lead to misleading evaluations and implications for the structure's stability under investigation. A critical design parameter is the relative size of geological fractures to excavation size. For engineering purposes, the representative dimension of an engineering structure (e.g., the span of a tunnel, the height of a bench, the width of an underground cavern or shallow foundation) is usually divided by the mean spacing of joint sets. If the calculated value is equal or greater than a threshold value, the rock mass is often considered treatable as a continuous, homogenous material, and its mechanical properties can be assumed constant in all directions (isotropic). Therefore, its mechanical behavior can be modeled numerically using the equivalent continuum approach. However, if the calculated value is less than the specified value, the rock mass's behavior in which the structure exists should be modeled using more complex discrete numerical methods based on the constitutive discontinuum approach.

Loading [MathJax]/jax/output/CommonHTML/fonts/TeX/fontdata.js

Page $3 / 28$ 
For a particular problem, the need to use continuum or discontinuum methods depends on the size and scale of discontinuities to those of the problem under consideration. There is no universally accepted unique quantitative parameter to determine when one method should be preferred (Bobet et al. 2009). When the 'sample' of a rock mass is considered such that only a few joints are contained in the volume of interest, its behavior is likely to be highly anisotropic and considered discontinuous. If the sample size is many times greater than the size of the individual fragments, the effect of each particle (and hence the joints) is statistically leveled out, and the sample may be considered continuous (Deere et al. 1969). Several authors have discussed this matter. Deere et al. (1969) have tied the 'sample' size to the size of a tunnel from its stability behavior. The stability of a tunnel opened in a discontinuous material depends primarily on the character and spacing of the discontinuities. In contrast, the stability in a continuous material can be related to the intrinsic strength and deformation properties of the intact material. In this regard, they found that the size of the 'sample' related to a tunnel should be considered discontinuous "when the ratio of fracture spacing to a tunnel diameter is between the approximate limits of 1/5 and 1/100. For a range outside these limits, the rock may be considered continuous, though possibly anisotropic." Hoek et al. (1995) provided a well-known qualitative guide, which schematically presented the process of shifting from intact to heavily jointed rock masses. In Fig. 2, intact and heavily jointed rock masses are shown as suitable conditions for modeling with the continuum approach, while the remaining cases are more prone to being modeled using the discontinuum approach alone. Some researchers propose using representative elementary volume (REV) as a plausible alternative to quantitatively determine the relative size for engineering structures in which a rock mass essentially behaves as a continuous, homogenous, and isotropic material.

[Figure 2]

Das and Singh (2021a) conducted a parametric study to determine the influence of different bolt lengths and bolt diameters on the maximum induced boundary displacements in a jointed rock mass, using a numerical method based on finite element code. The simulation results showed that an increase in the bolt length did not significantly reduce the boundary displacement, whereas an increase in the bolt diameter substantially reduced the tunnel boundary displacement. Das and Singh (2021b) studied the stability of an underground tunnel excavated in a jointed rock mass using field investigation and numerical modeling. A series of finite element numerical simulations were conducted based on the field/laboratory data with different values of joint spacing. It was found that the joint spacing predominantly controlled the extent of deformation above the excavation. Liu et al. (2020) investigated the anisotropy and scale effects on the strength characteristics of the defected rock mass using a synthetic rock mass (SRM) method, which was coupled with the discrete element method (DEM) and discrete fracture network (DFN). The test results showed that defects in the rock mass played a vital role in failure mode and strength behavior. The REV size of the considered defected rock mass was found as $5 \times 10 \mathrm{~m}$, and the confinement level also influenced this size.

\subsection{REV and Its Assessment Procedures}


Scale dependency is an important and well-known issue in rock engineering practice (Hoek and Brown 1980; Heuze 1980; Schultz 1996; Yoshinaka et al. 2008; Cundall et al. 2008). Some methods are suggested in the literature to tackle the scale effects problem. An empirical relation was developed by Hoek and Brown (1980). Palmström (1995) proposed the continuity factor (CF) concept, which can be expressed as $C F=D_{t} / D_{b}$, where $D_{t}$ is the tunnel diameter, $D_{b}$ is the block diameter $\left(D_{b}=V_{b}{ }^{1 / 3}, V_{b}\right.$ is the block volume in $\mathrm{m}^{3}$ ). The ground conditions can be classified as discontinuous (blocky) or continuous. For a discontinuous (blocky) ground $(3<\mathrm{CF}<50)$, the behavior is controlled mainly by individual blocks and joints. For a continuous ground ( $\mathrm{CF} \leq 3$ for massive rocks) or ( $\mathrm{CF} \geq 50$ for highly jointed and/or tectonically disturbed rocks), the behavior is dominated by intact rock properties and imposed stress.

The concept of the relative scale was proposed by Schultz (1996) and Hoek and Brown (1997). REV or representative volume element (RVE) was suggested by many researchers (Long et al. 1982, Oda 1988, Min and Jing 2003, Pariseau et al. 2008, Wang et al. 2011, Wu and Kulatilake 2012, Zhang et al. 2012, Song et al. 2017, Huang et al. 2020). The REV concept for a rock mass is illustrated in Fig. 3.

[Figure 3]

The following definitions of REV or RVE can be found in the relevant geotechnical literature:

"The REV, when it does exist, can be used to define the minimum volume of a sampling domain beyond which the permeability of the sampling domain remains essentially constant" (Long et al. 1982).

"The REV of a statistically homogeneous rock mass is defined as the minimum volume beyond which any sub-mass behaves essentially like the whole rock mass" (Oda 1988).

"The scale beyond which strength becomes independent of the specimen size and/or the density of defects is known as the REV and is considered to be the minimum volume of rock needed to evaluate scale effects and to achieve repeatability of tests results" (da Cunha 1990).

"REV is defined as the minimum size of a rock structure beyond which mechanical properties of the rock remain basically constant' (Min and Jing 2003).

"... an RVE of a jointed rock mass is one so large that another joint more or less does not significantly change the equivalent properties of the considered volume" (Pariseau et al. 2008).

"The REV size corresponds to the minimum sample size beyond which, the calculated values of the elastic properties of the specific rock mass stop fluctuating" (Esmaieli et al. 2010).

"REV of jointed rock masses is a scale concept, which means that the mechanical properties of rock masses show random fluctuations with changes of space and volume. The mechanical properties of rock masses would stabilize when rock mass volume is larger than some threshold, so the threshold is defined as the REV of rock masses" (Wang et al. 2011). 
"REV is the threshold volume beyond which property measurements will approach a constant value and represent the equivalent behavior of the whole mass" (Wu and Kulatilake 2012).

"When the sample size is relatively small, the rock mass parameters vary strongly with increasing size of the sample. The parameters no longer vary when the sample size has increased to a critical value, which is the size of the RVE" (Zhang et al. 2012).

"When the rock mass size is larger than or equal to a certain value, the fluctuation of rock properties significantly decreases, and the equivalent continuum parameters can represent the properties of the rock masses. Accordingly, this critical cube size is defined as the REV' (Song et al. 2017).

The above-quoted statements reveal nuances in the researcher's definitions of the REV. This parameter can also be classified according to the application area into mechanical, hydrological, and geometrical types (Esmaieli et al. 2010, Zhang et al. 2012, Huang et al. 2020). Depending on the REV application type, the value calculated for one property cannot be applied to another. Subsequently, different researchers proposed different calculation methods to assess the REV.

Bear (1972) first proposed the concept of REV to study fluid flow in a porous medium. The first formal definition of REV for rocks was used by Hill (1963). According to his definition, REV should be structurally representative of the whole mass, and the sample should contain a sufficient number of discontinuities, which can be used to represent the mean and variance of all discontinuities. John (1969) suggests that a sample of about ten times the average (linear) size of the single units may be considered a uniform continuum. It is clear that this will depend greatly on the uniformity of the unit sizes in the material or the uniformity of the spacing of the discontinuities. For a unit of $1 \mathrm{~m}^{3}$, the size of the sample would be $10^{3}=$ $1000 \mathrm{~m}^{3}$.

Based on in situ plate-bearing tests on rock mass surfaces, Rocha and Da Silva (1970) suggested that REV should be several times greater than the mean joint spacing. Lama and Vutukuri (1978) argued that the REV size should be ten times larger than the average fracture length. Oda (1988) offered a method for the determination of REV based on the crack tensor concept. He found that the REV size must be three times larger than a typical length of joint traces. Another approximate indication for REV is based on the experience from large sample testing at the University of Karlsruhe, Germany, where a volume containing at least $5 \times 5 \times 5=125$ blocks is considered continuous (Mutschler and Natau, 1991). A relative scale was defined by Schultz (1996) as the ratio of the scale of excavation to the scale of fracturing. He recommended a relative scale of five to 10 times the engineering structure. Hoek and Brown (1997) simply stated that to apply their empirical strength criterion, "the slope or underground excavation should be large and the block size small in comparison, resulting in the appearance of a heavily jointed rock mass". However, they did not refer to a specific number for the REV size.

Pariseau et al. (2008) used REV techniques to facilitate model execution while running an FE model for a pit slope in a case study. They selected the REV size as a cube with an edge ten times the maximum joint Loading [MathJax]/jax/output/CommonHTML/fonts/TeX/fontdata.js pout three to four times the typical joint size in a 
columnar jointed rock mass. Esmaieli et al. (2010) selected the REV size as a cube with an edge ten times the maximum joint set spacing in massive sulfide ore. Wu and Kulatilake (2012) reported the REV size to be eight to 10 times the mean discontinuity size of a rock mass in a diversion tunnel. Zhang et al. (2012) determined REV using the volumetric fracture density $\left(\mathrm{P}_{32}\right)$ calculation method at a dam site. They calculated the REV size as a cube with a $12 \mathrm{~m}$ side length in DEM model simulations. Song et al. (2017) determined the REV size as $15 \mathrm{~m}$ based on the 3D fracture persistence in a dam site.

Hoek and Brown (2019) proposed that the volume of interest for the REV size when deciding whether GSI should be used in their empirical criterion could be obtained by counting the number of rock blocks exposed on the tunnel or slope face. They suggested a REV size of five to 20 times for tunnels and five to 33 times for slopes using average joint spacing. As Cai et al. (2004) defined, the concept of equivalent spacing can be used to estimate the average volume of equivalent rock blocks. Sari (2019) illustrated the REV size on a cut slope where three orthogonal joint sets intersected the rock mass. The number of exposed blocks on the slope face was counted in this study, as Hoek and Brown (2019). In this slope, the mean equivalent block size, $V_{b}$, was found to be $0.025 \mathrm{~m}^{3}$, and the REV size was calculated as $84.25 \mathrm{~m}^{3}$ using a value ten times higher than the mean joint length. The overall slope volume was equal to 1,625 $\mathrm{m}^{3}$. Since the slope's volume was much greater than the REV size of individual blocks forming the rock mass (see Fig. 4), the rock mass's behavior in the cut slope was modeled using the equivalent continuum approach in FE analysis. In a recent study, Huang et al. (2020) proposed a new indicator to estimate the fractured rock mass REV size based on the Geological Strength Index (GSI) classification. It was found that the GSI-based REV size (7-14 m) of a block in the PFC-based synthetic rock mass (SRM) model was relatively larger compared with the traditional UCS and E-based REVs $(5-10 \mathrm{~m})$.

[Table 1]

[Figure 4]

\subsection{Numerical Methods in Rock Mass Modeling}

Most of the failure criteria for heavily jointed rock masses are based on the very few actual experimental tests of these masses, and hence most are empirical. In recent years, there has been a trend toward simulating the behavior of heavily jointed rock masses using numerical methods. Numerical modeling is a great tool for providing a solid understanding of the rock mass behavior both before and during excavation. The safest option for any analysis dealing with jointed rock mass might be to employ distinct element methods (DEM). In this process, the orientation of rock fractures, rock quality, and hydrogeology should be determined to develop an appropriate numerical model. Then, the intact rock's geomechanical properties can be used as the required input parameters to represent intact blocks in the DEM simulation. Including discontinuities in the analysis explicitly and properly defining their spatial distribution and mechanical parameters ensures that the model essentially replicates the behavior of a jointed rock mass. For a more comprehensive discussion on DEM in rock engineering applications, the readers can refer to the works of Ming and Jing (2003), Bobet et al. (2009), Esmaieli et al. (2010), Wu and Kulatilake (2012), 
Although DEM is a state-of-the-art technique for determining the behavior of jointed rock masses under in-situ loading conditions, the developments in numerical modeling, such as shear strength reduction, automatic means for generating fracture networks, numerical formulations for joint behavior, and widespread availability of computing power have also allowed performing a practical analysis of discontinuous media with the FE analysis (Hammah et al. 2009). The FE analysis uses the equivalent continuum approach, which assumes that the macroscopic behavior of fractured rock masses can be described by the principles of continuum mechanics, as long as its constitutive relations and associated properties/parameters can be properly established according to the basic laws of continuum mechanics (Ming and Jing 2003). The FE method can be combined with the shear strength reduction (SSR) technique to evaluate the safety factor of engineering structures (Dawson et al. 1999, Roosta et al. 2005, Hammah et al. 2008, Shen and Karakus 2014, Gupta et al. 2016). In this method, the FE analysis program systematically searches for a strength reduction factor, i.e., the factor of safety (FoS), which brings a slope or an underground structure to the very limits of failure (FoS $\leq 1.0)$.

The SSR technique described in the literature employs the Mohr-Coulomb strength criterion for rock materials. For Mohr-Coulomb material, the factored or reduced shear strength can be determined using the following equations:

$$
\frac{\tau}{F O S}=\frac{C^{\prime}}{F O S}+\sigma^{\prime} \frac{\tan \phi^{\prime}}{F O S}
$$

$$
\frac{\tau}{F O S}=c^{*}+\sigma^{\prime} \tan \phi^{*}
$$

where $c^{*}=c^{\prime} /$ FoS and $\phi^{*}=\arctan \left(\tan \phi^{\prime} /\right.$ FoS $)$ are the reduced Mohr-Coulomb shear strength parameters.

REV size is a quantitative measure of the volume of interest in which a rock mass essentially behaves as a continuous, homogenous, and isotropic material. The need to use continuum or discontinuum methods for a particular problem depends on the REV size calculation. The focus should be on the right choice of the numerical modeling of rock mass behavior. Once the REV size is determined, using the equivalent continuum approach in numerical modeling is advantageous if the problem under consideration satisfies the minimum REV size criterion. In this regard, FE analysis can help to achieve accurate forecasts of rock mass behavior.

This study aims to assess the cut-off REV size using FE numerical models adopting the equivalent continuum approach. A ratio between the size of the engineering structure and pre-existing joint spacing, which are the two most important contributing parameters in the REV size assessment, is numerically searched. Depending on the engineering structure's characteristic size to the joint spacing ratio, a 
threshold value of REV size is proposed based on numerical analysis. In an attempt to provide a correct approach, different descriptors were defined for this property.

\section{Illustrative Numerical Examples}

To provide a more systematic approach to the determination of REV size, a numerical study was undertaken. For this purpose, four different hypothetical engineering cases were executed using RS2 v. 9.0 (Rocscience Inc., 2018), a two-dimensional FE program for modeling geotechnical excavations:

- The first case demonstrated the effects of different slope heights on the REV size for a surface mine slope with $5 \mathrm{~m}$ joint spacing.

- The second case investigated the effects of various joints spacing values on the REV size for a single bench with a $25 \mathrm{~m}$ height.

- The third case explored the effects of various joint spacing values on the REV size for an underground circular opening with a $5 \mathrm{~m}$ diameter.

- The last case examined the effects of different joint spacing values on the REV size for an underground powerhouse cavern with a width of $30 \mathrm{~m}$ and a height of $75 \mathrm{~m}$.

In all cases, it was assumed that a systematic change in joint spacing values to the relevant dimension of the engineering structure would have a definite impact on the response of these structures caused by REV size. In this context, three different approaches were utilized by incorporating the effects of weak planes (joints) into the FE simulations:

- In the first approach, the problem domain (i.e., rock mass) was assumed to be free of any plane of weakness (i.e., no joints).

- In the second, the planes of weakness were explicitly represented by adding a joint network to the problem domain. RS2 has the capability of automatically generating discontinuity networks and joint sets in the FE analysis. This program can directly incorporate the same explicit definition of a joint network into a DFN-based analysis. Several types of joint networks, e.g., parallel, Voronoi, Veneziano, Baecher, and cross-jointed, can be defined in the program.

- In the third approach, the planes of weakness were implicitly represented by embedded joints in the constitutive model of rock material. A constitutive model developed for the commercial FE package, RS2, considers the Mohr-Coulomb criterion for the matrix and includes three sets of weak planes for the material. It was assumed that the weak planes were uniformly distributed in the medium. Here, the strength reduction factor was applied to the Mohr-Coulomb criterion for the material and the Coulomb criterion for the weak planes or joints by reducing the shear strength with the SSR factor. The spacing between these weak planes in the control volume of the material was small enough to ensure that the matrix and weak planes' combination could be smeared to an equivalent anisotropic material (Azami et al. 2012). 
- The same material and joint properties listed in Table 2 were used in all FE models.

- The discontinuities and the intact rock behavior were modeled using the Mohr-Coulomb slip criterion with peak and residual strengths.

- Two orthogonal joint sets oriented at $45^{\circ}$ and $-45^{\circ}$ from the horizontal plane were defined.

- For the two-dimensional plane strain case, each set had infinite uniform parallel joints.

- Six-noded uniform triangular meshes with an increased mesh element density at the bench face were used for surface benches, and the graded types were utilized for underground structures.

- A constant in-situ stress field of $10 \mathrm{MPa}$ ( $400 \mathrm{~m}$ depth) in horizontal and vertical directions with a ratio of $k=1$ was assumed for underground structures and an actual field stress for surface benches.

- Initial joint deformation was allowed, and the joint ends were open at boundary and excavation contact points.

- The external boundary of structures at the right, left, and bottom edges were fixed in the $X$ and $Y$ directions, while the surface boundary was free to move in the $X$ and $Y$ directions.

- The distance of the external boundary from the toe and crest was set as the bench height for surface structures.

- A box with dimensions three times greater than the structure's diameter or width was applied for farfield boundaries for underground structures.

- The exposure of rock mass to groundwater or dynamic effects (earthquake and blasting vibrations) was not considered.

[Table 2]

It is important to determine which descriptors can correctly assess (reflect) the scale effect. The previous studies considered changing mechanical, physical, and geometrical properties for REV size determination. This study assumes that the numerical models of engineering structures can provide significant variations in total displacement and safety factor measures in response to changing joint spacing values under in-situ loading conditions. Therefore, total displacement measurements and safety factors in FE models are chosen as plausible descriptors in the following sub-sections.

\subsection{The Case of an Open Pit Slope}

In this example, a hypothetical open pit mine slope with a constant joint spacing of $5 \mathrm{~m}$ was simulated for various slope heights ranging from $5 \mathrm{~m}$ to $500 \mathrm{~m}$. Table 3 presents the results of safety factor and total displacement calculations obtained from the numerical analysis. As the height of the slope increased, the safety factor was reduced. The results also showed that the presence of the joints in the rock mass considerably reduced the safety factor of the slopes. Similar findings were also reported by Hammah et al. (2009) and Sari (2019). A ratio calculated by dividing the slope height by the joint spacing value is given in the same table to emphasize the size effect. Figure 5 reveals that the distribution of total dicnlanomont nountore chiftod from a ranular nirnular nattern to a thin-layered pattern parallel to the Loading [MathJax]/jax/output/CommonHTML/fonts/TeX/fontdata.js 
bench face as the density of joints increased in the rock mass. This implies that as the intensity of joints in the rock mass increases, the failure surface moves from a circular to a tabular form. On the other hand, it is known that the larger (referring to the ratio of slope height to joint spacing or length) a slope, the closer the failure mechanism to the rotational-type slip failures, as in soil. The reason for observing such a layered displacement pattern in highly jointed rock masses needs further explanation, which is beyond the scope of this research.

[Table 3]

[Figure 5]

\subsection{The Case of a Single Bench}

In this example, a hypothetical single bench slope with a constant height of $25 \mathrm{~m}$ was examined for different joint spacing applications ranging from $20 \mathrm{~m}$ to $0.5 \mathrm{~m}$. In the previous example, the joint spacing was kept constant at a certain value to observe the REV size's possible effect on the slope height changes. In contrast, the bench height was kept constant, and different joint spacing values were realized to explore the REV size's possible effect. Table 4 presents the results of safety factor and total displacement calculations obtained from the numerical analysis. As the joint density was increased in the rock mass, no consistent pattern was observed in these values. Figure 6 shows that the distribution of total displacement counters shifted from circular to a thin-layered shape along the slope face as the density of joints was increased in the rock mass, similar to the previous case. This implies that as the intensity of joints in the rock mass increases, the failure surface shifts from a circular to a layered form. Again, this was not consistent with the commonly reported pattern in previous geotechnical studies.

[Table 4]

[Figure 6]

\subsection{The Case of a Circular Opening}

In this case study, a hypothetical underground circular opening with a diameter of $5 \mathrm{~m}$ and joint spacing values ranging from $10 \mathrm{~m}$ to $0.25 \mathrm{~m}$ were analyzed. Table 5 presents the result of the safety factor and total displacement calculations obtained from the numerical analysis. As the intensity of joints was increased in the rock mass, no consistent pattern was observed in the results, but the distribution of total displacement counters shifted from a regular circular pattern to an x-shaped pattern, which was in agreement with the joint set orientations obtained from the numerical models (Fig. 7). A similar pattern was also noted for the embedded joints.

[Table 5]

[Figure 7]

\subsection{The Case of an Underground Cavern}


For this part of the study, a hypothetical underground powerhouse cavern with the dimensions of $30 \mathrm{~m}$ width and $75 \mathrm{~m}$ height was examined at joint spacing values from $50 \mathrm{~m}$ to $1 \mathrm{~m}$. Since this structure was significantly larger than the previous circular opening case, it was expected to respond differently to the changing joint spacing values. Table 6 presents the results of the safety factor and total displacement calculations obtained from the numerical analysis. It was determined that as the intensity of joints increased in the rock mass, the safety factor values regularly decreased in contrast to the circular opening case. This can be attributed to the significantly larger size of the cavern compared to the circular opening. Figure 8 reveals that the distribution of total displacement counters shifted from a regular circular pattern to an $x$-shaped form as the density of joints increased in the rock mass, which is compatible with the joint sets' orientations in the numerical model. A similar displacement pattern was also noted for the embedded joints.

[Table 6]

[Figure 8]

\section{General Evaluation And Discussions}

This section aims to provide a general evaluation of the results found separately in the previous section for four different cases. Figures 5 to 8 demonstrate that discontinuities and their density significantly altered the shape of total displacement distributions around the rock mass. The shape of the expected failure surface shifted from a circular pattern to a layered pattern for surface structures because of the increased density of joints in the rock mass. The shape of the total displacement distribution shifted from a circular to an $\mathrm{x}$-shaped pattern for underground structures, reflecting the joint set orientations defined in the rock mass. However, it is worth noting in all figures that the largest scale effects considering total displacement counters were seen in the wider joint set spacings. Concerning the safety factor values given in Tables 3 to 6 , when a regular decreasing trend was observed as the density of joints increased in the rock mass in cases of an open pit slope and underground cavern, there was no regular trend in the remaining cases (circular opening and single bench). This may be due to the scale effect, considering that the first two cases were significantly larger in the excavation dimension than the last two. During the numerical model simulations, it was observed that as the density of joints increased in the rock mass, the computing time also increased exponentially. Although it was initially planned to run additional simulations for more closely spaced joint sets, this was impossible due to the excessive demand for computer memory and speed.

Figures 9 to 12 present the safety factor and total displacement measurements obtained from three different approaches employed during FE simulations to represent the rock mass's joint sets. When these figures were examined, the first impression was that depending on the type of engineering structure investigated and the measurement method, it was very hard to explicitly determine a cut-off value for the REV size. However, a careful look at these figures reveals a specific point on the joint network line where tho ratin of onninoorina ctrunturo cizo tn inint cnanina value converged to the corresponding ratio Loading [MathJax]/jax/output/CommonHTML/fonts/TeX/fontdata.js

Page $12 / 28$ 
calculated for the embedded joints. This specific point can be assumed as the cut-off size of REV for both the factor of safety and total displacement parameters. As indicated with a red arrow on the graphs, the REV sizes of the safety factor and total displacement were around 30 and 48, respectively for the open-pit slope, 23 and 24, respectively for the single bench and 15 and 8, respectively for the underground cavern. In the case of a circular opening, both values were 2 .

Inherent difficulties in obtaining REV and diverse range of its application areas resulted in reporting a wide array of values for this property, as seen in Fig. 13. Besides, the structures opened close to the surface or deep underground affect the REV size estimation. Due to changing levels of the induced stresses, the mechanical behavior of rock structures shows significant variations under diverse geoenvironmental conditions. Low stresses effective on the surface structures led the discontinuities to control the failure and deformation behavior of rock masses. Therefore, the range of REV values found in this study (23.5-39) for surface structures is significantly larger than the commonly reported range of values (5-10) in the relevant geotechnical literature. Hoek and Brown (2019) reported a similar range of values considering the REV size of 5-33 suggested for the slopes.

However, for underground structures, the failure and deformation of rock masses were mainly driven by strain-induced stresses. Due to confined space, discontinuities do not have enough room to play a significant role in controlling rock mass behavior. Similarly, the range of REV size values (2-11.5) found in this study was compatible with most reports in the relevant geotechnical literature (Fig. 13). Hoek and Brown (2019) suggested a range of values (5-20) for the tunnels. As a final remark, the calculated global average of 19.0 (Table 7) can be recommended as a unique threshold REV size for surface and underground structures exhibiting scale-dependent behavior.

[Table 7]

[Figure 9]

[Figure 10]

[Figure 11]

[Figure 12]

[Figure 13]

\section{Conclusions And Future Work}

This study was one of the first attempts to define threshold values for the REV size using the equivalent continuum approach. Surface and underground structures with various sizes were investigated numerically regarding their possible responses to the changing joint spacing values in the surrounding rock mass. The following conclusions were obtained from the study. 
- It was found that depending on the type of engineering structure and descriptor used, the structures responded differently due to the scale effect.

- The commonly reported REV size range (5-10) in the relevant geotechnical literature in Table 1 is significantly smaller than the values found in this study. For general purposes, a range of values (15-20) as the threshold value for REV size can be more rational for rock structures exhibiting scaledependent behavior.

- In any engineering excavations in/on rock masses satisfying this ratio (i.e., size of the structure divided by the mean joint spacing) or above, the surrounding rock mass can be assumed to be continuous, homogenous, and isotropic material (i.e., heavily jointed rock mass in Fig. 2) and its failure behavior can be sufficiently modeled by an FE analysis using the equivalent continuum approach.

- However, if the calculated ratio is less than REV as mentioned above value, it is better to model the behavior of the rock mass using more complex discontinuum approaches. Key block theory (Goodman \& Shi 1989), discrete fracture network (Dershowitz et al. 2000), synthetic rock mass (Mas Ivars et al., 2011), discontinuous deformation analysis (Shi 1993), and ELFEN (Eberhardt et al. 2004) are some of the possible alternatives.

- It is important to determine whether a material should be considered continuous or discontinuous in a particular case. Accordingly, the type of behavior of the material may be predicted, from which suitable failure criteria and design methods may be employed in numerical models. In this regard, it may also be mentioned that the current approach to modeling engineering projects in a jointed rock mass is to treat the rock as a discontinuum (controlled by individual joints) in the near field of an opening and as a continuum in the far-field (when the volumes are significantly larger).

The following improvements can be recommended to the research undertaken in the future.

- For surface slopes, since this study only considered the bench slope angle of $45^{\circ}$, different slope angles should be investigated to determine the effect of REV size on slope stability.

- Besides a circular shape for underground openings, other opening shapes can also be analyzed in a more detailed study.

- In all numerical models evaluated in this study, the rock masses' structural defects were represented by two orthogonal joint sets oriented at $45^{\circ}$ and $-45^{\circ}$ to the horizontal plane. Various fracture networks' arrangements should also be investigated in further research to obtain more solid background knowledge.

- Rather than only having Mohr-Coulomb material type in FE models, other types of material models, especially non-linear Hoek-Brown, should also be examined to determine the optimal REV size in rock masses exhibiting scale-dependent behavior.

\section{Declarations}


Declaration of Competing Interests: The authors declare that they have no known competing financial interests or personal relationships that could have appeared to influence the work reported in this paper.

\section{References}

Azami A, Yacoub T, Curran JH (2012) Effects of strength anisotropy on the stability of slopes. In: GeoManitoba 2012.

Bear J (1972) Dynamics of Fluids in Porous Media. Amsterdam: Elsevier.

Bobet A, Fakhimi A, Johnson S, Morris J, Tonon F, Yeung MR (2009) Numerical models in discontinuous media: review of advances for rock mechanics applications. J Geotech Geoenvirn Engng 135(11):154761.

Cai M, Kaiser PK, Uno H, Tasaka Y, Minami M (2004) Estimation of rock mass deformation modulus and strength of jointed hard rock masses using the GSI system. Int J Rock Mech Min Sci 41(1):3-19.

Cundall P, Pierce ME, Mas Ivars D (2008) Quantifying the size effect of rock mass strength. In: Proc. 1st Southern Hemisphere International Rock Mechanics Symposium, pp. 3-15, Perth: Australian Centre for Geomechanics.

Da Cunha AP (1990) Scale effects in rock masses. Pinto da Cunha A (ed) Proceedings of the First International Workshop on Scale Effects in Rock Masses, Loen, 7-8 June 1990.

Das R, Singh TN (2021a) Effect of rock bolt support mechanism on tunnel deformation in jointed rockmass: a numerical approach. Underground Space, doi: 10.1016/j.undsp.2020.06.001

Das R, Singh TN (2021b) Effect of closely spaced, non-persistent ubiquitous joint on tunnel boundary deformation: a case study from Himachal Himalaya. Geotechnical and Geological Engineering, 39, 24472459.

Dawson EM, Roth WH, Drescher A (1999) Slope stability analysis by strength reduction. Geotechnique 49(6): 835-40.

Deere DU, Peck RB, Monsees JE, Schmidt B (1969) Design of tunnel liners and support systems. Office of High-Speed Ground Transportation, US Department of Transportation, PB 183799.

Dershowitz WS, La Pointe PR, Doe T (2000) Advances in discrete fracture network modeling. In: Proc. of the US EPA/NGWA Fractured Rock Conference - info.ngwa.org, pp. 882 - 94.

Eberhardt E., Stead D., Coggan J.S. (2004). Numerical analysis of initiation and progressive failure in natural rock slopes-the 1991 Randa rockslide. Int J Rock Mech Min Sci 41:69-87. 
Esmaieli K, Hadjigeorgiou J, Grenon M (2010) Estimating geometrical and mechanical REV based on synthetic rock mass models at Brunswick Mine. Int J Rock Mech Min Sci 47(6):915-26.

Goodman RE, Shi GH (1985) Block theory and its application to rock engineering. London: Prentice-Hall, $338 \mathrm{pp}$.

Gupta V, Bhasin RK, Kaynia AM, Kumar V, Saini AS, Tandon RS, Pabst T (2016) Finite element analysis of failed slope by shear strength reduction technique: a case study for Surabhi Resort Landslide, Mussoorie township, Garhwal Himalaya. Geomatics, Natural Hazards and Risk 7(5):1677-90.

Hammah RE, Yacoub T, Corkum B, Curran JH (2008) The practical modelling of discontinuous rock masses with finite element analysis. In: 42nd US Rock Mechanics Symposium, pp. 56-63.

Hammah RE, Yacoub T, Curran JH (2009) Variation of failure mechanisms of slopes in jointed rock masses with changing scale. In: 3rd CANUS Rock Mechanics Symposium (Paper No. 3956). Toronto.

Heuze FE (1980) Scale effects in the determination of rock mass strength and deformability. Rock Mechanics Felsmechanik Mecanique Des Roches, 12 (3-4):167-92.

Hill R (1963) Elastic properties of reinforced solids: some theoretical principles. Journal of the Mechanics and Physics of Solids 11:357-72.

Hoek E, Brown ET (1980) Underground Excavation in Rock. The Institution of Mining and Metallurgy, London.

Hoek E, Brown ET (1997) Practical estimates of rock mass strength. Int J Rock Mech Min Sci 34(8):1165-86.

Hoek E, Brown ET (2019) The Hoek-Brown failure criterion and GSI - 2018 edition. Journal of Rock Mechanics and Geotechnical Engineering, 11(3):445-463.

Hoek E, Kaiser PK, Bawden WF (1995) Support of Underground Excavations in Hard Rock.

Huang H, Shen J, Chen Q, Karakus M (2020). Estimation of REV for fractured rock masses based on Geological Strength Index. International Journal of Rock Mechanics and Mining Sciences, 126, 104179.

Hudson JA, Harrison JP (1997) Engineering rock mechanics. Oxford: Elsevier.

John KW (1969) A civil engineering approach to evaluate strength and deformability of regularly jointed rock. 11th Int. Symp. on Rock Mech. pp. 69-80.

Lama RD, Vutukuri VS (1978) Handbook on properties of rocks. Berlin: Borntraeger.

Liu X, He S, Wang D (2020) Numerical analysis of the anisotropy and scale effects on the strength 
Long JCS, Remer JS, Wilson CR, Witherspoon PA (1982) Porous media equivalents for networks of discontinuous fractures. Water Resour Res 18(3):645-58.

Martin CD, Kaiser PK, McCreath DR (1999) Hoek-Brown parameters for predicting the depth of brittle failure around tunnels. Canadian Geotechnical Journal 36(1), 136-151.

Mas Ivars D (2010) Bonded Particle Model for Jointed Rock Mass. Ph.D. Thesis, KTH-Engineering Geology and Geophysics Research Group, Royal Institute of Technology (KTH).

Mas Ivars D, Pierce ME, Darcel C, Reyes-Montes J, Potyondy DO, Paul Young R, Cundall PA (2011) The synthetic rock mass approach for jointed rock mass modelling. Int J Rock Mech Min Sci 48(2):219-44.

Min KB, Jing L (2003) Numerical determination of the equivalent elastic compliance tensor for fractured rock masses using the distinct element method. Int J Rock Mech Min Sci 40(6):795-816.

Mutschler T, Natau O (1991) Further developments for the determination of the stress-strain behavior of jointed rock mass by large-scale tests. Proc. of 7th ISRM Congress, Aachen, pp. 1557-1560.

Ning Y, Xu WY, Zheng WT, Meng GT, Shi AC, Wu GY (2008) Study of random simulation of columnar jointed rock mass and its representative elementary volume scale. Chin J Rock Mech Eng 27:1202-08.

Oda M (1988) A method for evaluating the representative elementary volume based on joint survey of rock masses. Canadian Geotechnical Journal 25(3):440-7.

Palmström A (1995) RMi - A rock mass characterization system for rock engineering purposes. Doctoral dissertation, University of Oslo.

Pariseau WG, Puri S, Schmelter SC (2008) A new model for effects of impersistent joint sets on rock slope stability. Int J Rock Mech Min Sci 45(2):122-31.

Rocscience Inc. (2018). RS2 (Version 9.0) Finite element analysis for underground excavations and slopes. Rocscience Inc. Toronto, Canada. http://www.rocscience.com.

Rocha M, Da Silva JN (1970) A new method for determination of deformability of rock masses. Proceedings of 2nd Congress on Rock mechanics, International Society for Rock mechanics, Belgrade, pp. 2-21.

Roosta RM, Sadaghiani MH, Pak A (2005) Strength reduction technique in stability analysis of jointed rock slopes. International Journal of Civil Engineering 3(3-4):152-65.

Sainsbury BL, Sainsbury DP (2017) Practical use of the ubiquitous-joint constitutive model for the simulation of anisotropic rock masses. Rock Mech Rock Engng 50(6):1507-28.

Salmi EF (2019) Researchgate answer submitted to question "Is there any need for up-scaling lab rock Loading [MathJax]/jax/output/CommonHTML/fonts/TeX/fontdata.js mechanics?", Accessed 20 March 2019. 
Sari M (2019) Stability analysis of cut slopes using empirical, kinematical, numerical and limit equilibrium methods: case of old Jeddah-Mecca road (Saudi Arabia). Environmental Earth Sciences 78(21):621

Schultz RA (1996) Relative scale and the strength and deformability of rock masses. Journal of Structural Geology 18(9):1139-49.

Shen J, Karakus M (2014) Three-dimensional numerical analysis for rock slope stability using shear strength reduction method. Canadian Geotechnical Journal 51(2):164-72.

Shi G-H (1993) Block system modeling by discontinuous deformation analysis. Computational Mechanics Publications, Southampton UK.

Song SY, Sun FY, Chen JP, Zhang W, Han XD, Zhang XD (2017) Determination of RVE size based on the 3D fracture persistence. Q J Engng Geol Hydrogeol 50:60-8.

Wang X, Zhao Y, Lin X (2011) Determination of mechanical parameters for jointed rock masses. J Rock Mech Geotech Engng 3:398-406.

Wu Q, Kulatilake PHSW (2012) REV and its properties on fracture system and mechanical properties, and an orthotropic constitutive model for a jointed rock mass in a dam site in China. Computers and Geotechnics 43:124-42.

Yoshinaka R, Osada M, Park H, Sasaki T, Sasaki K (2008) Practical determination of mechanical design parameters of intact rock considering scale effect. Engineering Geology 96(3-4):173-86.

Zhang W, Chen J, Liu C, Huang R, Li M, Zhang Y (2012) Determination of geometrical and structural representative volume elements at the Baihetan Dam site. Rock Mech Rock Engng 45(3):409-19.

\section{Figures}




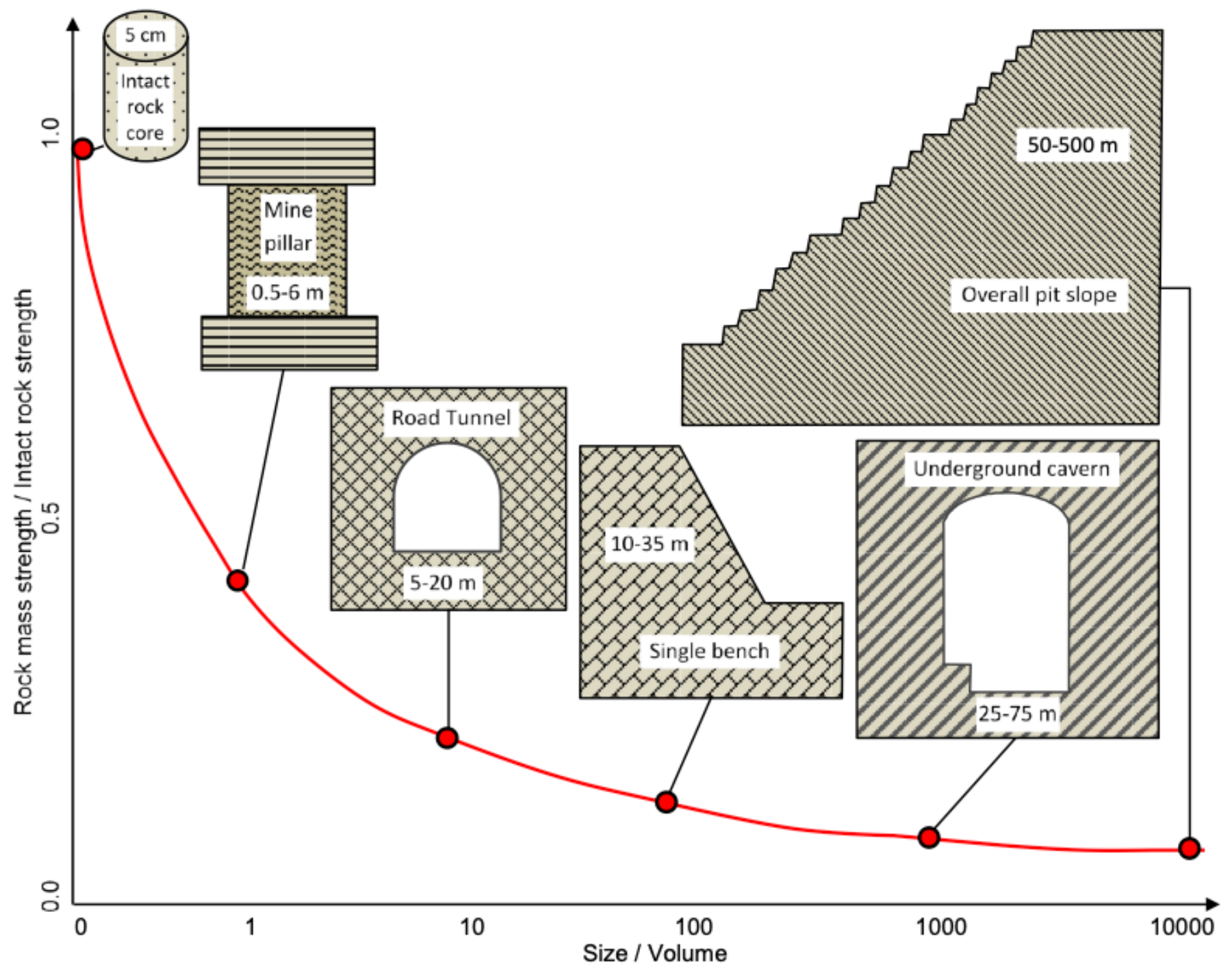

\section{Figure 1}

Typical examples of rock structures in civil and mining applications exhibiting scale-dependent behavior (When size or volume of interest increases, the control of strength behavior can range in a wide spectrum from a simple brittle failure of intact rock in a laboratory core specimen to a complex mass-controlled failure of heavily jointed rock in an open pit slope). 


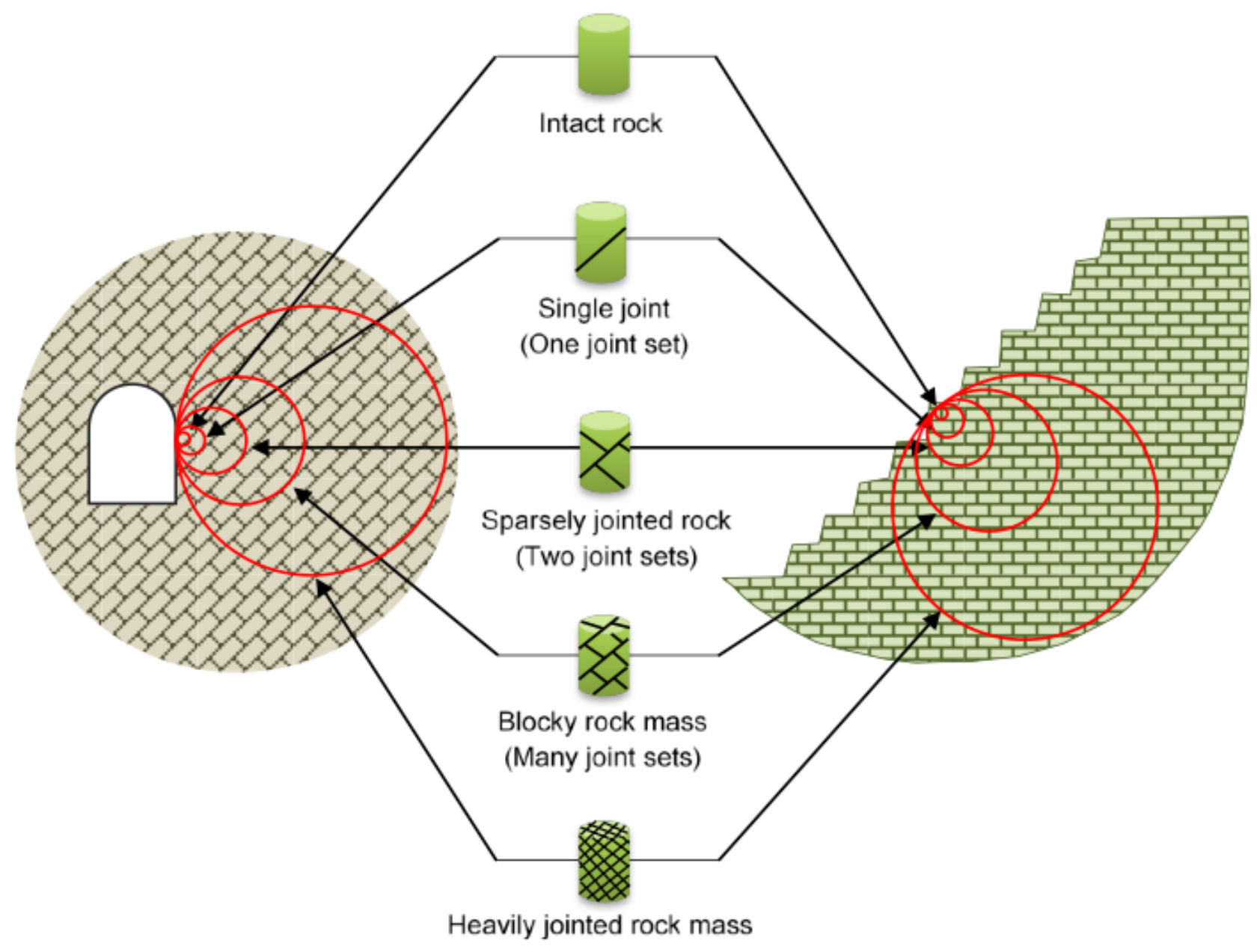

Figure 2

The scale-dependent in-situ transition of an intact rock mass to a heavily jointed rock mass in the cases of underground excavation (left) and open pit slope (right) (modified after Hoek et al. 1995).

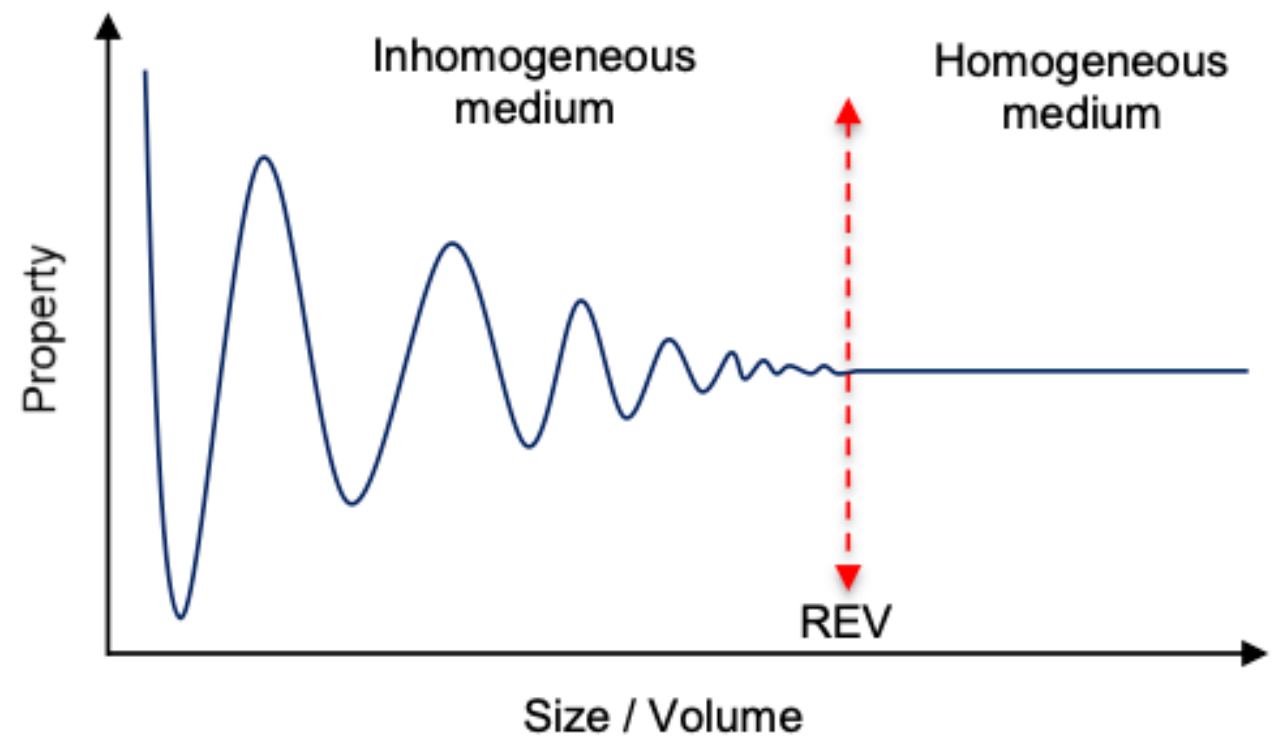




\section{Figure 3}

The REV concept (after Hudson and Harrison 1997).

$\mathrm{V}=84.25 \mathrm{~m}^{3}$

$\mathrm{N}=3,370$ blocks

$V_{b}=0.025 \mathrm{~m}^{3}$

In situ block

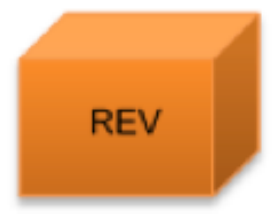

$\mathrm{V}=1,625 \mathrm{~m}^{3}$

$\mathrm{N}=65,000$ blocks

\section{Figure 4}

Schematic illustration of the relative sizes of an in situ rock block, REV, and slope face along with a road cut (not to scale) (modified after Sari 2019). 

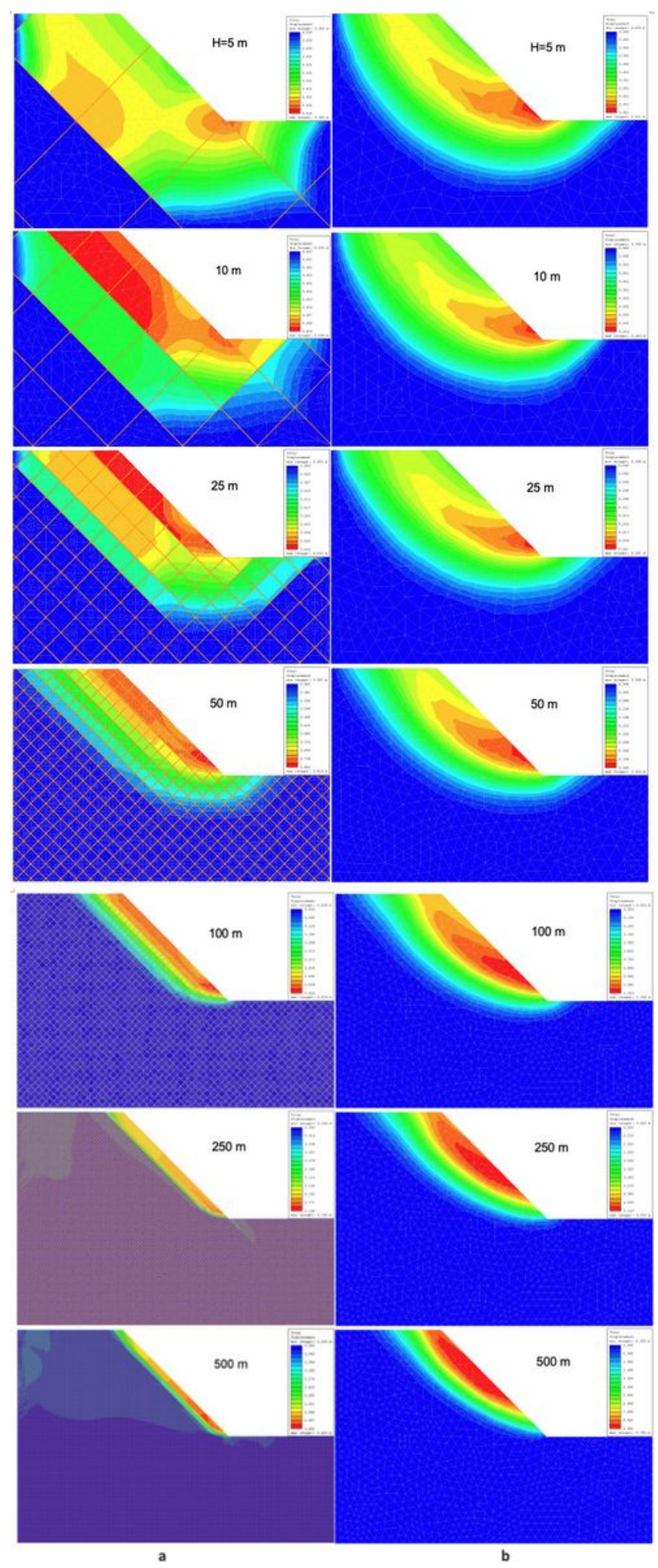

\section{Figure 5}

Total displacement counters of a rock mass in an open-pit mine at an increasing slope height $(\mathrm{H}=5 \mathrm{~m}$, $10 \mathrm{~m}, 25 \mathrm{~m}, 50 \mathrm{~m}, 100 \mathrm{~m}, 250 \mathrm{~m}$, and $500 \mathrm{~m})$, a Constant joint spacing (S = 5 m), b No joints 

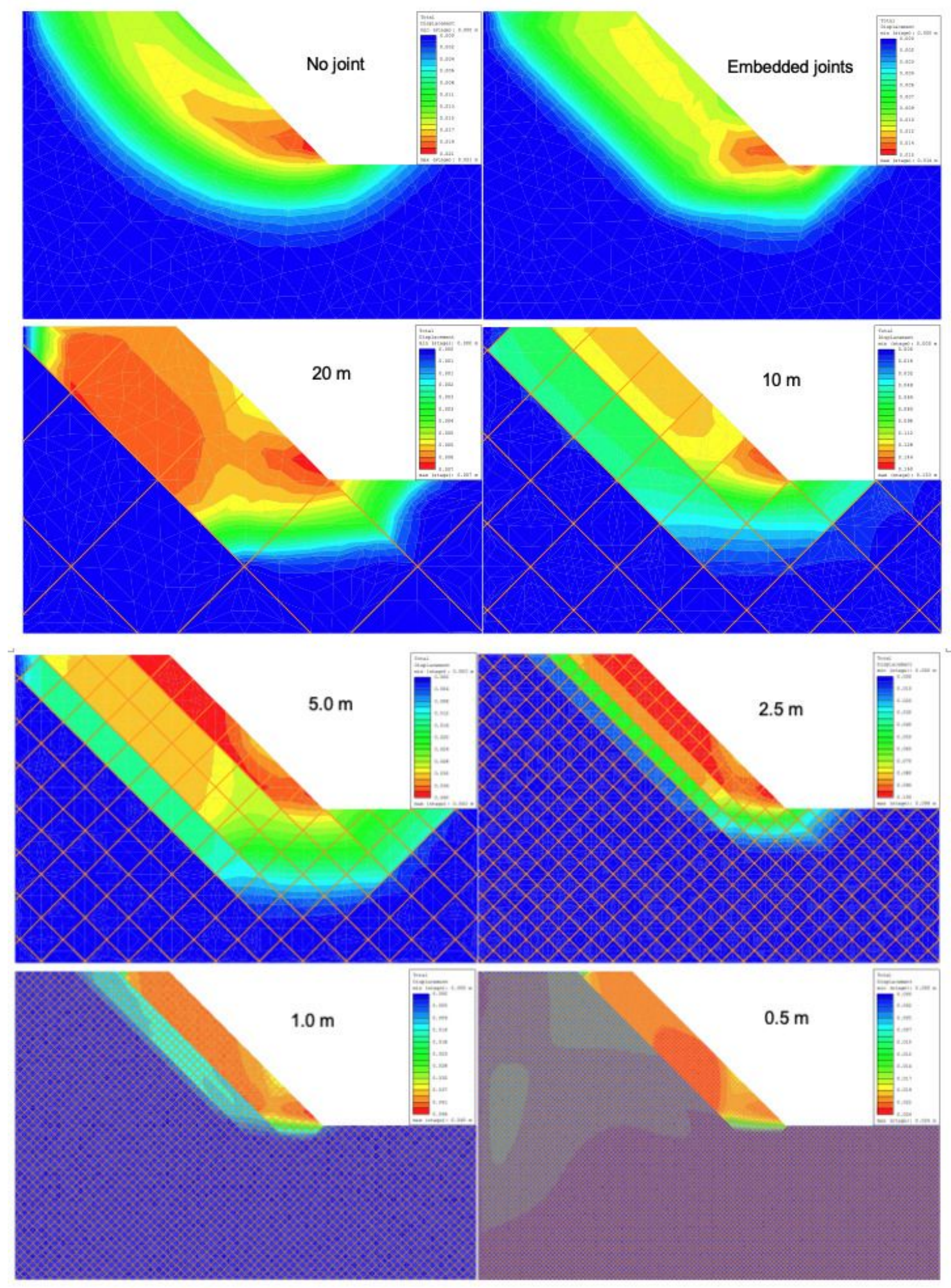

\section{Figure 6}

Total displacement counters of a rock mass in a bench at a constant height $(\mathrm{H}=25 \mathrm{~m})$ and decreasing joint spacing values $(\mathrm{S}=20 \mathrm{~m}, 10 \mathrm{~m}, 5 \mathrm{~m}, 2.5 \mathrm{~m}, 1.0 \mathrm{~m}$, and $0.5 \mathrm{~m})$. 

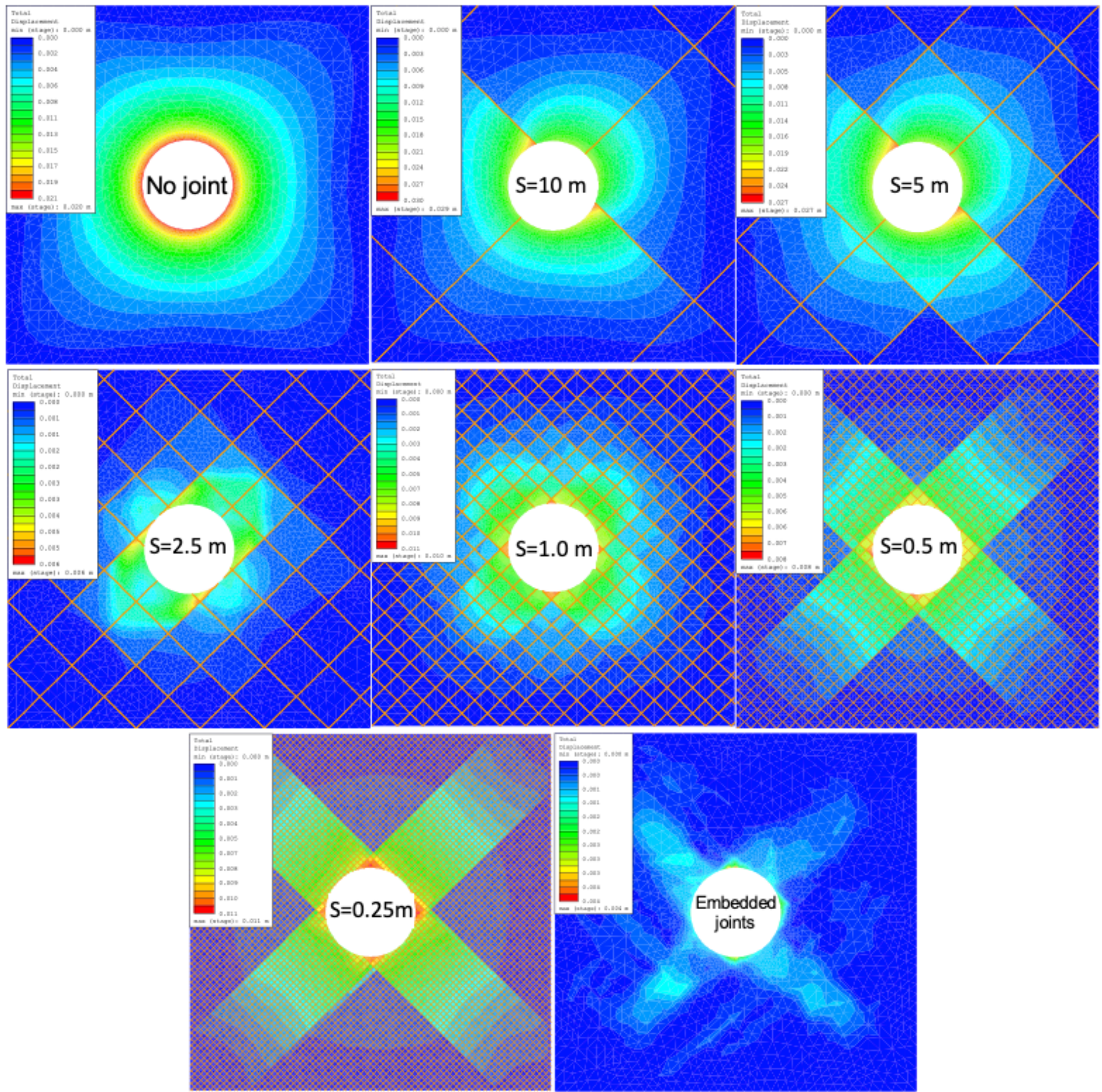

\section{Figure 7}

Total displacement counters of a rock mass in a circular opening with a constant diameter $(D=5)$ at decreasing joint spacing values ( $\mathrm{S}=10 \mathrm{~m}, 5 \mathrm{~m}, 2.5 \mathrm{~m}, 1.0 \mathrm{~m}, 0.5 \mathrm{~m}$, and $0.25 \mathrm{~m}$ ). 

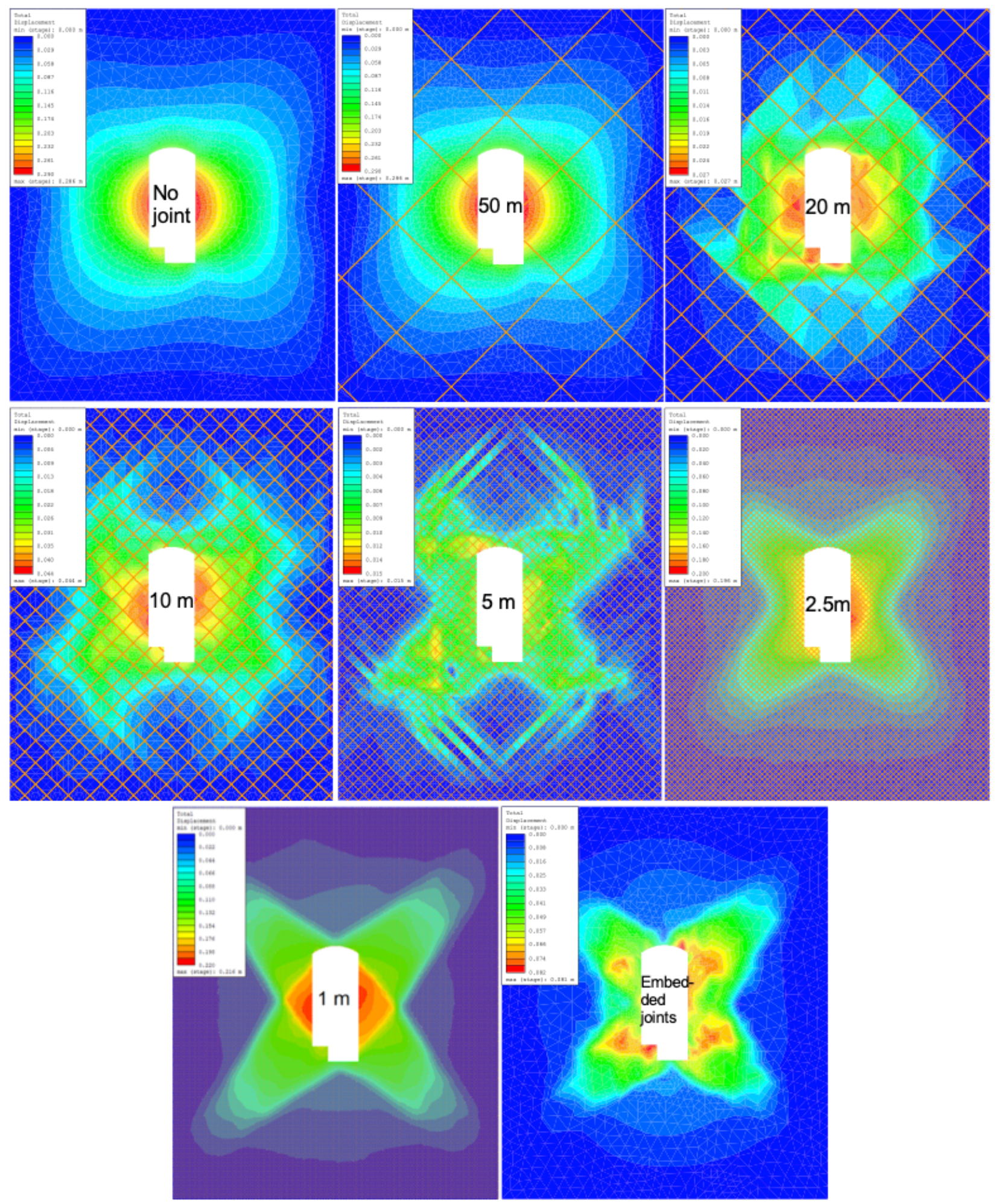

\section{Figure 8}

Total displacement counters of a rock mass in an underground cavern with a dimension of $30 \mathrm{~m}$ width and $75 \mathrm{~m}$ height at decreasing joint spacing values ( $\mathrm{S}=50 \mathrm{~m}, 20 \mathrm{~m}, 10 \mathrm{~m}, 5 \mathrm{~m}, 2.5 \mathrm{~m}$, and $1 \mathrm{~m})$. 


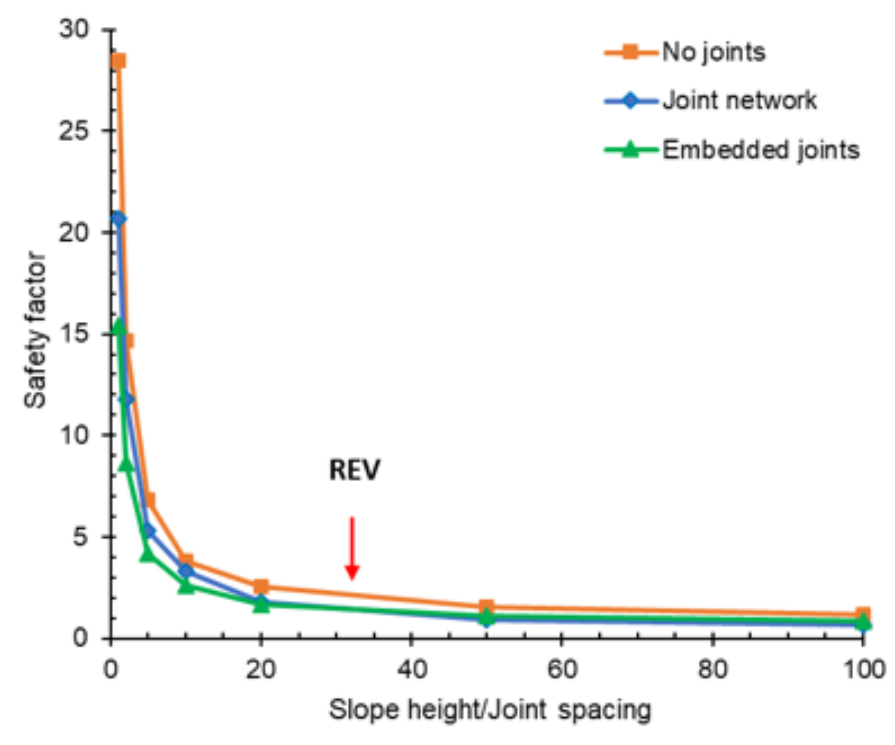

a

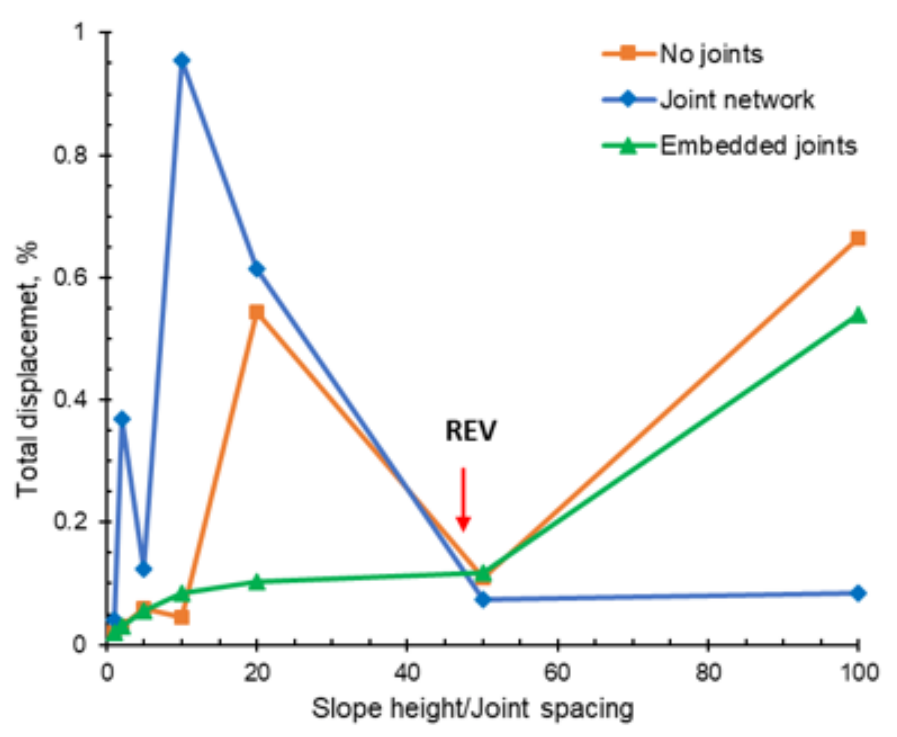

b

\section{Figure 9}

REV size for an open-pit mine with various height/joint spacing ratios, a Safety factor, b Total displacement.

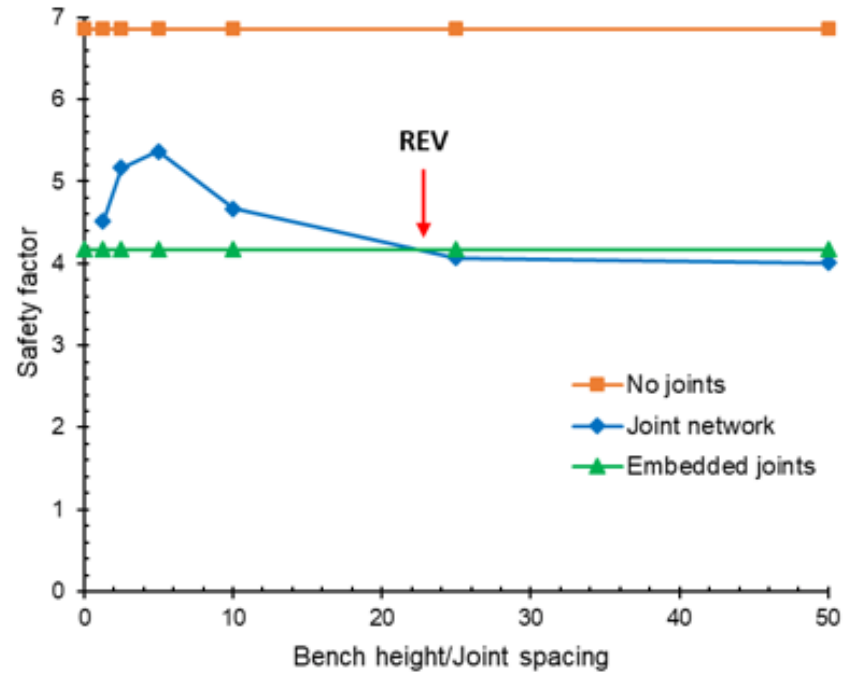

a

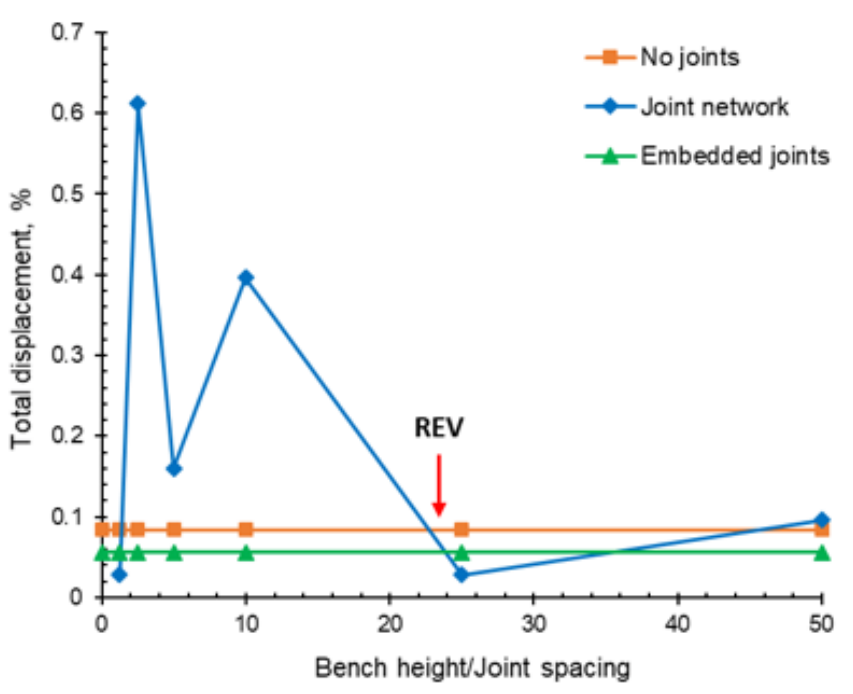

b

\section{Figure 10}

REV size for a single bench with various height/joint spacing ratios, a Safety factor, b Total displacement. 


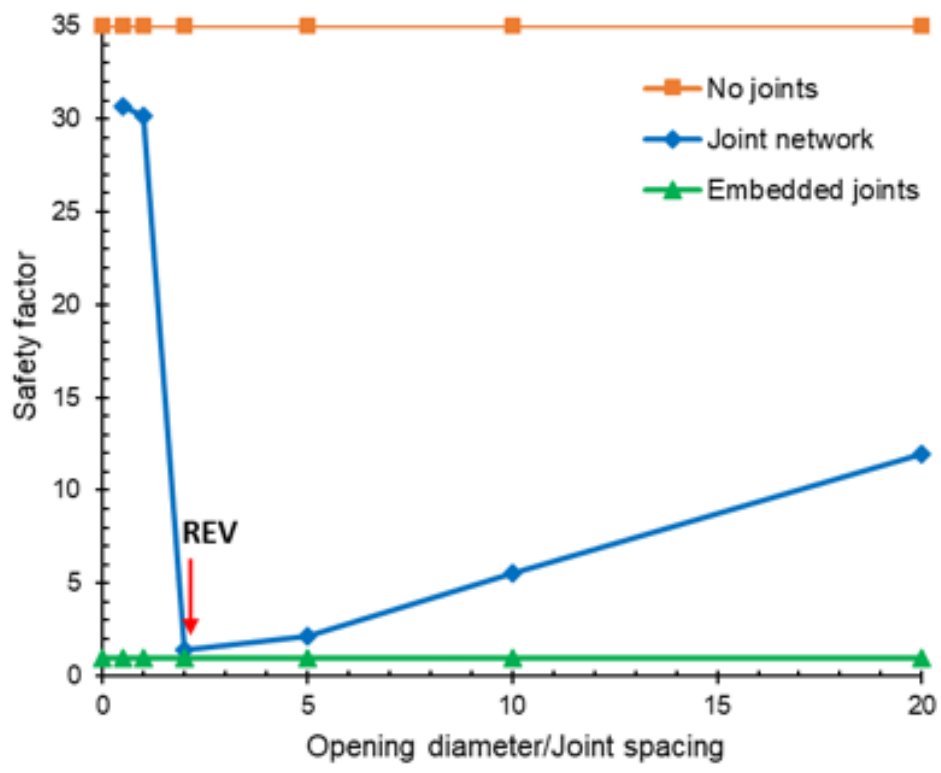

a

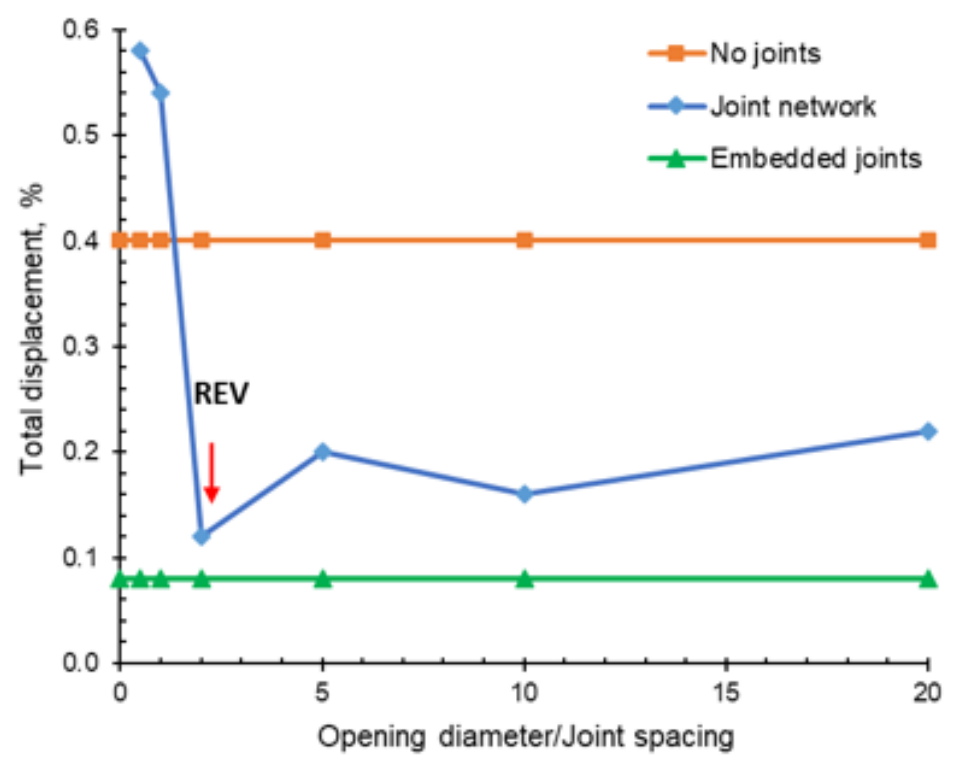

b

\section{Figure 11}

REV size for a circular opening with various diameter/joint spacing ratios, a Safety factor, b Total displacement.

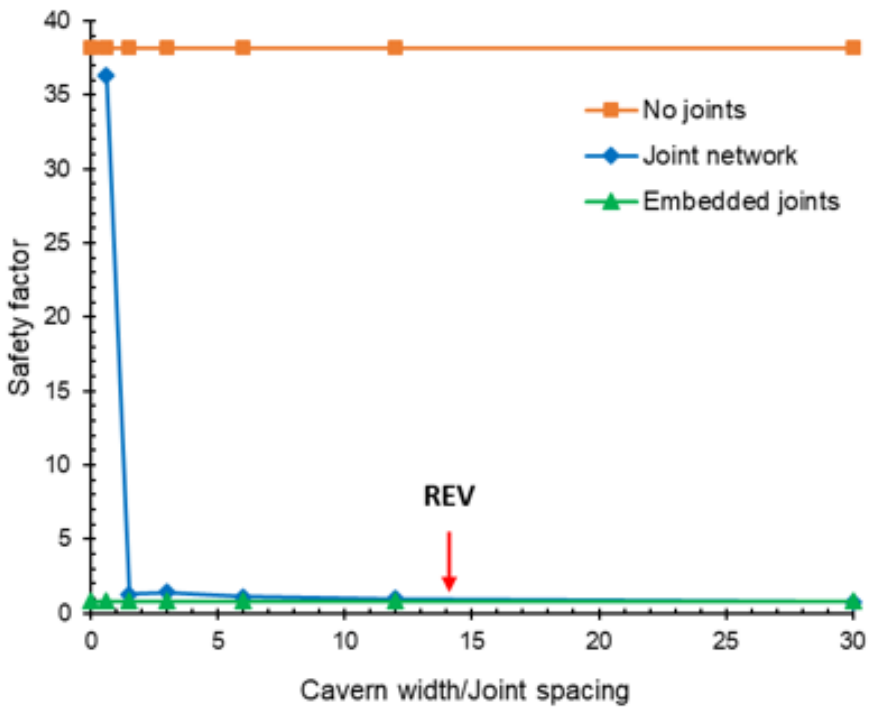

a

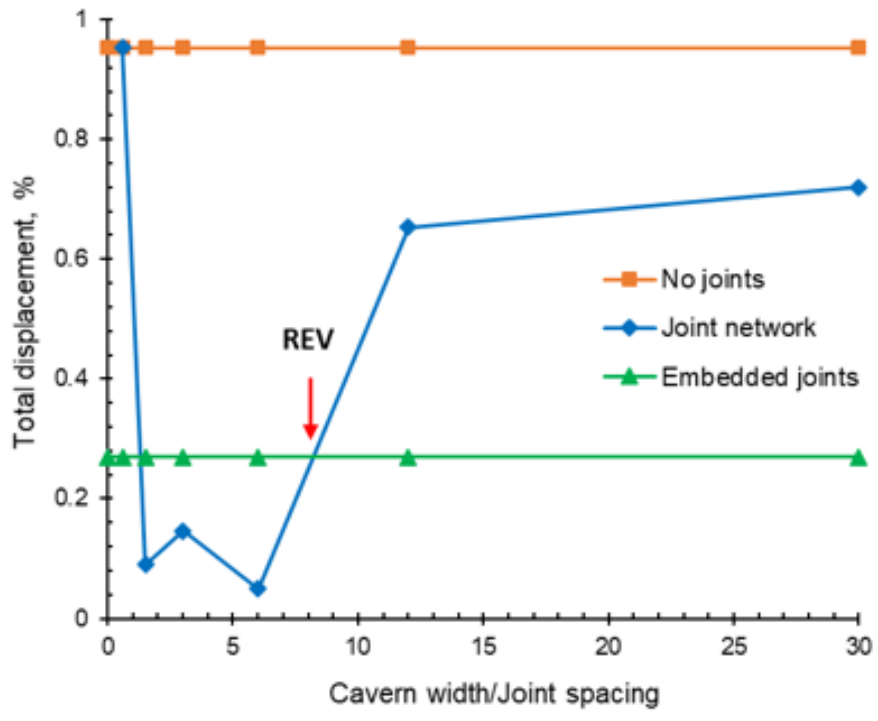

b

\section{Figure 12}

REV size for an underground cavern with various width/joint spacing ratios, a Safety factor, b Total displacement. 


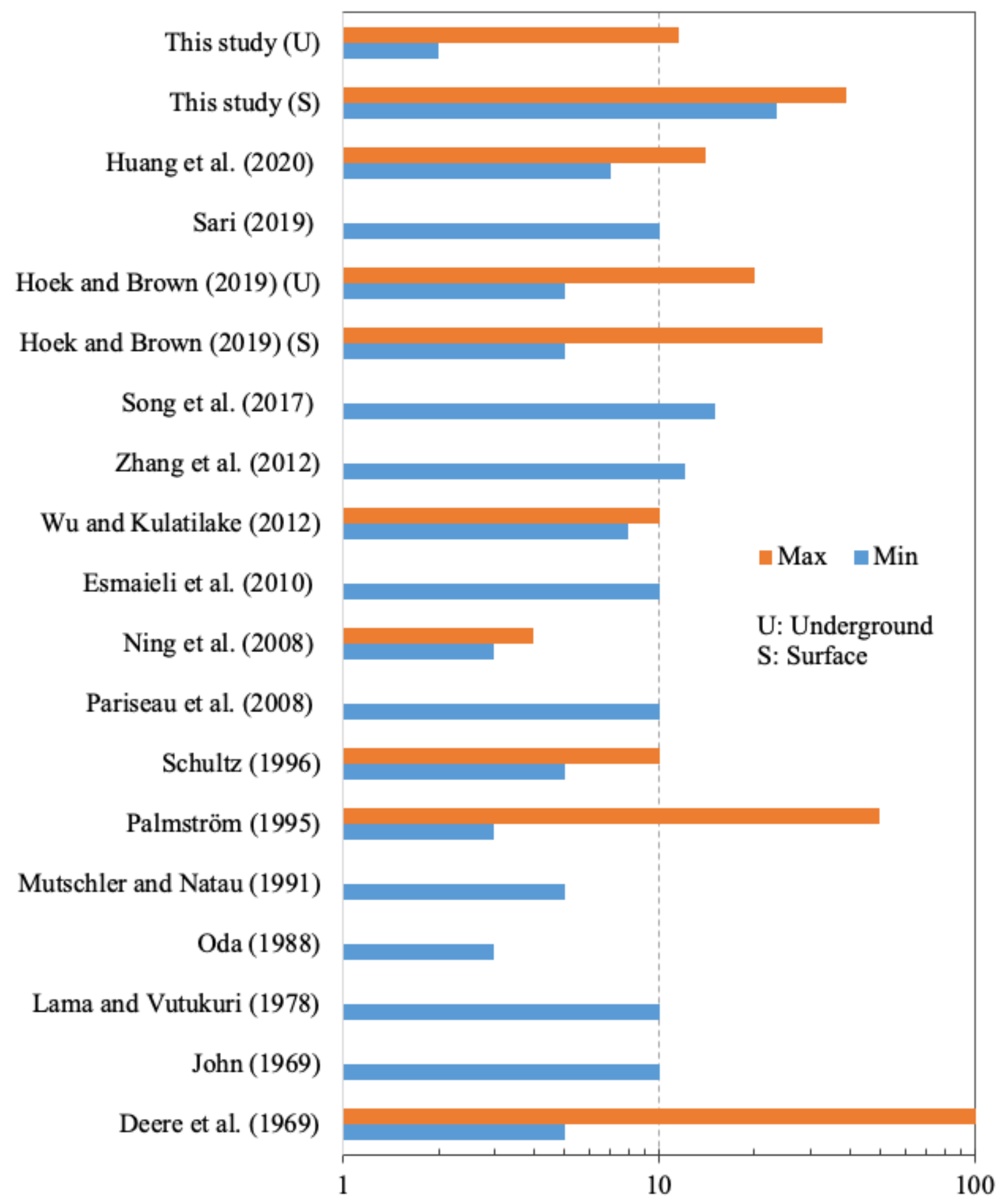

Figure 13

Comparison of REV size ranges proposed by different researchers. 